\title{
Innovative Care Model for Non Communicable Disease Patients on Patient Waiting Times in Peripheral Health Clinic in Base Hospital, Elpitiya
}

\author{
Lasantha Krishan Hirimuthugoda ${ }^{1, ~ *}$, Hewa Kasakara Diwela Wannakuge Miyasiya Gajanayaka ${ }^{2}$, \\ Vithanage Narada Channa ${ }^{3}$, Induwarie Harsha Gajanayaka Hewa Kasakara Diwala Wannakuge, \\ Vithanage Milinda Chanaka Perera ${ }^{5}$, Suranga Paranagamage ${ }^{6}$
}

\author{
${ }^{1}$ Department of Community Medicine, Post Graduate Institute of Medicine, University of Colombo, Colombo, Sri Lanka \\ ${ }^{2}$ Department of Non-communicable Disease, Institute of Regional Director of Health Services, Hambantota, Sri Lanka \\ ${ }^{3}$ Outpatient Department, Base Hospital, Diyathalawa, Sri Lanka \\ ${ }^{4}$ Outpatient Department, District Hospital, Bandarawela, Sri Lanka \\ ${ }^{5}$ Department of Public Health, Institute of Regional Director of Health Services, Badulla, Sri Lanka \\ ${ }^{6}$ Department of Public Health, Institute of Regional Director of Health Services, Hambantota, Sri Lanka
}

\author{
Email address: \\ krishan824@yahoo.com (L. K. Hirimuthugoda) \\ ${ }^{*}$ Corresponding author
}

\section{To cite this article:}

Lasantha Krishan Hirimuthugoda, Hewa Kasakara Diwela Wannakuge Miyasiya Gajanayaka, Vithanage Narada Channa, Induwarie Harsha Gajanayaka Hewa Kasakara Diwala Wannakuge, Vithanage Milinda Chanaka Perera, Suranga Paranagamage. Innovative Care Model for Non Communicable Disease Patients on Patient Waiting Times in Peripheral Health Clinic in Base Hospital, Elpitiya. European Journal of Clinical and Biomedical Sciences. Vol. 4, No. 3, 2018, pp. 46-50. doi: 10.11648/j.ejcbs.20180403.12

Received: January 28, 2018; Accepted: August 2, 2018; Published: August 31, 2018

\begin{abstract}
Long queue and long waiting time for taking appointment, consulting a doctor and to get drugs is a critical problem to patients with Non-communicable diseases who are following in government health sector. Many primary healthcare services in Sri Lanka is delivered through vertical systems, where services for routine issuing appointment, consultation and issuing drugs are co-located but use separate physical space, staff and medical records. Aim of the research leads to integration of the systems deteriorates the waiting time and reduces the worse health outcomes in the long run. A care model was developed integration of consultation and issuing drugs, with permanent issuing of routine appointment in rural healthcare settings, Elpitiya. Data on waiting time of patients during two seven-day periods before and six months after the integration were collected using a time and motion study. Statistical tests were conducted to investigate whether the two observation periods differed in operational details such as staffing, patient arrival rates, mix of patients etc. Previous level of attendance was analysed by their clinic records (before intervention). Multiple linear and logistic regression repeated measures analyses were used to assess the program's effects. Comparison of raw data showed that waiting times decreased by 7.2 hours to 3 hours, after integration $(\mathrm{p}<0.01)$. Clinic patients attendance was remarkably improved with regular clinic service after implementing appoint system from $35 \%-60 \%$ to $85 \%-90 \%$. The rate of clinic attendance was increased dramatically over the period from 6 months. Waiting time for attending clinic was declined and waiting in lines were avoided. Moreover, the intervention did improve clinic utilization and satisfaction. Integrating health services have the potential of reducing waiting times due to more efficient use of resources. Encouraging patients by new model is challenging and does appear to provide significant realistic benefits at rural, resource poor health settings beyond those provided by basic clinic services.
\end{abstract}

Keywords: Patients Waiting Time, Care Model, Non Communicable Disease, Rural Health Care 


\section{Introduction}

Today, non communicable diseases (NCDs), mainly cardiovascular diseases, cancers, chronic respiratory diseases and diabetes represent a leading threat to human health and development. These four diseases are the world's biggest killers, causing an estimated 35 million deaths each year $60 \%$ of all deaths globally - with $80 \%$ in low- and middleincome countries. [1]

NCD prevention is an all-government responsibility. Considerably more gains can be achieved by influencing policies of non-health sectors than by health policies alone. All stakeholders will need to intensify and harmonize their efforts to avert these preventable conditions and to save millions from suffering needlessly and dying prematurely. [1]

Historically, many NCDs were associated with economic development and so-called "diseases of the rich". However, today an estimated $80 \%$ of the four main types of NCDs cardiovascular diseases, cancers, chronic respiratory diseases and diabetes - occur in low- and middle-income countries. The prevention and control of NCDs is becoming increasingly important on the global health agenda.

Non communicable disease, its complications and deaths due to that is becoming the most measurable cost for the national budget and real heavy burden to family and country. Its complications are the most accountable one out of those three mentioned above, because it is the one really complicating the natural ongoing life style of the patients as well as the family members.

Many hospitals around the world apply solutions to overcome the problem of long waiting times in outpatient clinics such as hospitals in the USA, China, Sri Lanka, and Taiwan [2]. These clinics have succeeded in reducing wait times by $15 \%, 78 \%, 60 \%$ and $50 \%$, respectively [2]. Such solutions depend mainly on adding more human resources or changing some business or management policies. Creating practical and sustainable systems to provide care for this growing population is one of the most pressing challenges facing health care planners and policy makers in resource limited settings today. The waiting list was longer for visiting subspecialists than specialities is less than specialists but the demand for visiting by subspecialists is not less too [3]. Many primary healthcare services in sub-Saharan Africa are delivered through vertical systems, where services for tuberculosis, routine outpatient care, maternal and child health and family planning are co-located but use separate physical space, staff and medical records [4- 5]. Despite these accomplishments, a limitation of this integrated service delivery model was an increase in waiting times for all outpatients, including those enrolled in HIV care and treatment as well as those seeking non-HIV services [6]. Since waiting time experienced by patients has been shown to adversely affect their health seeking behavior [7- 8] and treatment adherence [9], increased waiting times were perceived to be a barrier to, or at least limitation of, scaling up this service-delivery model. All participants made stark comparisons in terms of 'waiting for' and 'waiting in' public and private hospitals. The perceptions outlined in this section did not vary on the basis of the urgency of the treatment or surgery required by participants [10].

\section{Methodology}

General objective of study was to assess the waiting time of the patients who have gone new innovative clinic model in the medical clinics for Non Communicable Diseases, Base hospital, Elpitiya 2015. Study Design was an experimental Design and study Setting was in the medical clinics in peripheral unit, Base Hospital, Elpitiya 2015. The daily patient load, calculated from attendance figures recorded in the clinic's registers, were approximately 220. Average staffing levels at the clinic per four-hour shift across both departments comprised 2-3 parmacist, 1-2 nurses and 3-4 clinicians (clinical officers and physician). The clinic was operating in twice a week between 8 am to $12 \mathrm{pm}$. Study population was all patients who were following at medical clinics, Base Hospital, Elpitiya during 2015. Patients who regularly followed up in medical clinics without default more than 6 months were included and patients followed with the support of hospital staff officer or followed under staff numbers, patients followed as religious leaders, patients who need ward admission or need further investigation and patients who are not categorized under Annexure 1 (As a Non-communicable disease) were excluded from the study. Sample was selected to represent the all clinic patients (about 2000). Usually less than 5 hour waiting time before the intervention is $10 \%$. ( the time period between arriving time to clinic and leaving time from the clinic after taking the drugs). Target of the study is to improve the clinic waiting time less than 5 hours in more than $50 \%$ of clinic patients. So the effect size will be $40 \%$. $(50 \%-10 \%)$.

Sample size was based on the following formula

$$
N=\underline{\left[Z \alpha / 2+Z_{1}-\beta\right]\left[P_{1}\left(1-P_{1}\right)+P_{2}\left(1-P_{2}\right)\right]}
$$$$
\left(P_{1}-P_{2}\right)
$$

$\mathrm{N}=$ Sample size

Zà $/ 2=$ this depends on level of significance, for $5 \%$ this is 1.96

$\mathrm{z} 1-\beta=$ This depends on power, for $80 \%$ this is 0.84

$\mathrm{P} 1=50 \% ; \mathrm{P} 2=10 \%$

Calculated sample size was at 238 Patients. So the control was 238 and interventional group will be 238 and total sample was 476. Sampling Method was all patients who are regularly followed up more than 6 months until the sample size completed. Method of Intervention was all the patients who are followed up more than 6 months regularly (without default) was recruited for the study.

Drew the chart of typical patient flow in the medical clinic and identify the places where they have to wait in queues for the service. It is as below. 

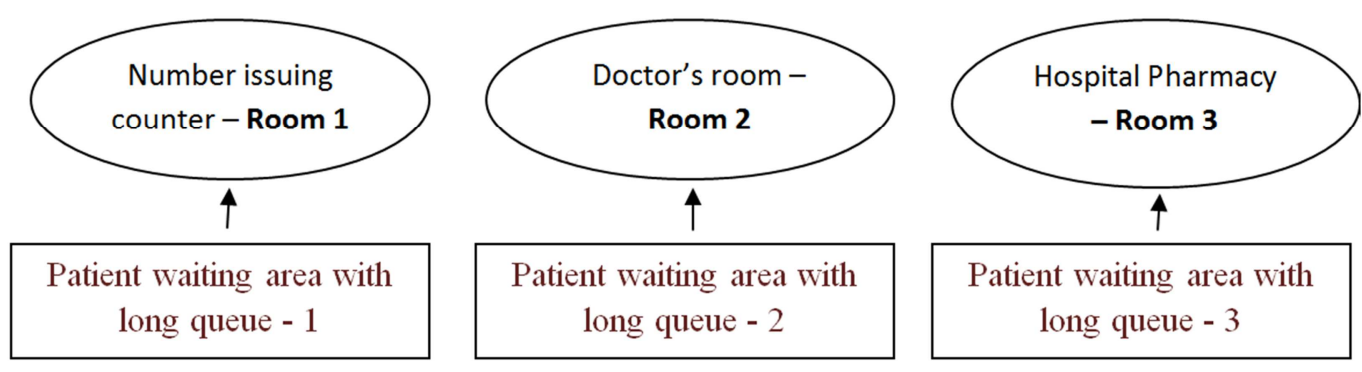

Figure 1. Patients flow in the medical clinic before the intervention and before the integration.

\subsection{Step 01}

In usual medical clinic Base hospital Elpitiya, patients had to come at early morning (before $4.00 \mathrm{am}$ ) or day before evening (around $5.00 \mathrm{pm}$ ) to follow the line to take a number to consult a doctor. Because, there were so many patients above the level of capacity of medical clinic. It is same in all over the country in government hospitals in Sri Lanka. After taking the number, they had to follow another queue to consult a doctor in separate area. Then, all the patients had to wait in the third queue to take their drugs from the pharmacy in some other place. Study recorded the different times of the patients of starting and ending to follow the queue to take a number, to consult a doctor and to collect their drugs. It was as follows.

Table 1. Chart used to document starting and finishing time of different queues before the intervention.

\begin{tabular}{|c|c|c|c|c|c|c|c|}
\hline & $\begin{array}{l}\text { Start of following } \\
\text { the queue at } \\
\text { room } 1 \text { (Time) }\end{array}$ & $\begin{array}{l}\text { End of following } \\
\text { the queue at } \\
\text { room1 (Time) }\end{array}$ & $\begin{array}{l}\text { Start of following } \\
\text { the queue at room } \\
2 \text { (Time) }\end{array}$ & $\begin{array}{l}\text { Start of consulting } \\
\text { a doctor at room } 2 \\
\text { (Time) }\end{array}$ & $\begin{array}{l}\text { end of } \\
\text { consultation at } \\
\text { room } 2 \text { (Time) }\end{array}$ & $\begin{array}{l}\text { Start of following } \\
\text { the queue at room } \\
3 \text { (Time) }\end{array}$ & $\begin{array}{l}\text { End of following } \\
\text { the queue at room } \\
3 \text { (Time) }\end{array}$ \\
\hline $\begin{array}{l}\text { Patient } 1 \\
\text { Patient } 2 \\
\text { Patient } 3 \\
\text { Patient } 4\end{array}$ & & & & & & & \\
\hline
\end{tabular}

\subsection{Step 02}

It was planned to give the permanent number and appoint time (7 am on clinic days) to patients, who was selected for the study. Then, with the new settings, patients was not needed to follow the queue to take the number along the number issuing counter as they would be given a permanent number. Permanent number came with the color code and particular color code repeated after 4 weeks. So, research team was using 8 different colors as patients were having 8 clinic days per month. (Twice per week).

Patients was given the next date of their follow-up and color coded clinic dates was displayed in notice board for their use to remind.

It was identified that there were three patient waiting areas with long queues as number issuing counter, doctor's room and pharmacy were in three separate places. It had been planned to integrate room 2 and 3 in to one space to reduce the patients waiting time in queue No 2 and 3 . So the patients had to follow only one line to doctors' room, then they had to be seated outside till their number was called to collect their drugs by the pharmacy. Patient's drug card was directly passed to pharmacy via doctor's room without involvement of patients. (Before the intervention patients had to bring the card and follow the line for pharmacy) To implement this method, room 3 was moved in to the room 2 to render the service of issuing drugs by using the same space with doctors. Partition was used to separate the same space. Area of pharmacy was equipped with microphone and audio speakers to call over the patient's particular number to collect his/her drugs.

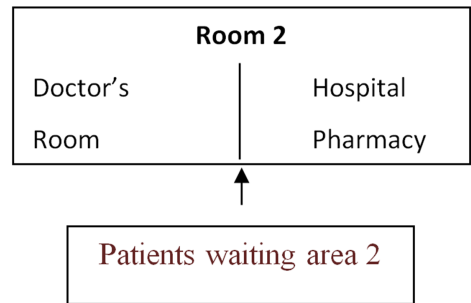

Figure 2. Patients flow in the medical clinic after the intervention and after the integration.

Table 2. Chart used to document starting and finishing time of different queues after the intervention.

\begin{tabular}{|c|c|c|c|c|}
\hline & $\begin{array}{l}\text { Start of following the queue at } \\
\text { room } 2 \text { (Time) }\end{array}$ & $\begin{array}{l}\text { Start of consulting a doctor at } \\
\text { room } 2 \text { (Time) }\end{array}$ & $\begin{array}{l}\text { End of consultation at room } 2 \\
\text { (Time) }\end{array}$ & $\begin{array}{l}\text { Issuing the drugs at room } \\
3 \text { (Time) }\end{array}$ \\
\hline \multicolumn{5}{|l|}{ Patient 1} \\
\hline \multicolumn{5}{|l|}{ Patient 2} \\
\hline \multicolumn{5}{|l|}{ Patient 3} \\
\hline Patient 4 & & & & \\
\hline
\end{tabular}


Time and Motion Study:

Research members conducted a time and motion study over two, eight-day periods (one month before integration and six months after integration) during the busiest clinic hours of 7:30 am to 12:00 noon. Specifically, the preintegration data was be collected from March 2013 and postintegration data will be collected from June 2013.

In each instance, a form was attached to patients' medical files to record the time of patient arrival and the start and end times of patient interaction at each clinic station (rooms) during the patient flow process. Two of the co-authors recorded the time of patient arrival in the clinic while the times at subsequent stations through the clinic was recorded by the respective healthcare workers attending the patients.

The difference between a patient's start and end times at each step was defined as his/her process time whereas the difference between the end time at one step and the start time at the subsequent step was defined as his/her waiting time for the next step.

It was assumed that a patient's whole stay in a room is part of the processing or consultation time and that the worker was idle between the end time of the previous patient and the start time of the subsequent patient. Hence, any time spent by the nurses with charts during a patient's stay in the room was assumed to be a part of the process time of that particular patient.

Due to limited number of resources in the clinic, team members noticed that staff availability per room changed during clinic hours. In order to account for this variability, the number of resources available per each room for different time intervals such as 60 minutes, 30 minutes and 15 minutes were investigated. It was decided to use 15 minutes intervals since it represented the fluctuations the best.

\section{Results}

Data were presented from patients waiting time, but not about patient, who drew on their experiences (rather than quantifying length) of waiting times, and the impact this had on their perception of hospital services and staff. Participants talked differently in qualitative component of this study, about 'waiting for' hospital appointments and surgery once referred, and 'waiting in' hospitals (e.g. waiting in emergency departments, waiting to see healthcare professionals once admitted) and how this differed between public and private hospitals. Participant's perceptions of the reasons for and acceptance of 'waiting for' or 'waiting in' hospitals impacted their trust in various social systems (e.g. government, hospitals) and healthcare professionals working within hospitals. Although participants' discussions of 'waiting for' and 'waiting in' hospitals may not map easily onto administrative definitions, research team provide contextual data to understand the impact of waiting times on patient experiences. It is important to provide this rich, contextual and meaningful data on the lived experiences of waiting in public and private hospitals, since "knowing more about what conditions produce trust and distrust, and why this matters, helps to craft the structure and financing of health care delivery in a manner that supports and enhances trust". This may provide a more comprehensive picture of how waiting time shapes trust and consequential attitudes and health behaviours relevant to healthcare expenditure. Participants in public hospitals had experienced much longer waiting times for hospital appointments and for elective surgery. The main reason for most participants not purchasing PHI was the cost, and most would have liked to for the purpose of reducing waiting for treatment, but could not afford to.

Comparison of raw data showed that waiting times decreased by 7.2 hours to 3hours, after integration $(\mathrm{p}<0.01)$. Clinic patients attendance was remarkably improved with regular clinic service after implementing appoint system from $35 \%-60 \%$ to $85 \%-90 \%$. The rate of clinic attendance was increased dramatically over the period from 6 months. Waiting time for attending clinic was declined and waiting in lines were avoided. Moreover, the intervention did improve clinic utilization and satisfaction.

Evaluation of the results showed a reduction in patient waiting time. When late doctor arrival issues were solved, this can reduce the clinic service time by up to $10 \%$.

\section{Conclusion}

Integrating health services have the potential of reducing waiting times due to more efficient use of resources. The consultant's attendance time has a direct impact on the patient's waiting time, especially for the first appointment both in the morning and the afternoon sessions. Encouraging patients by new model is challenging and does appear to provide significant realistic benefits at rural, resource poor health settings beyond those provided by basic clinic services.

\section{Abbreviations}

NCD: Non-communicable diseases

\section{Declarations}

Written informed consent was obtained from all subjects who agreed to take part in the study.

\section{Ethical Approval}

Ethical approval was taken from Ethics Review committee, Faculty of Medicine, University of Ruhuna.

\section{Consent for Publication}

Not applicable

\section{Availability of Data and Materials}

Presented with in manuscript as an additional file 


\section{Competing Interests}

The authors declare that they have no competing interests.

\section{Authors' Contributions}

LK and MG are responsible for reported research. Both authors have made substantial contributions to conception and design; analysis and interpretation of data and drafting and revising it critically for important intellectual content.

\section{References}

[1] 2008-2013 Action plan for the global strategy for the prevention and control of non communicable diseases. World Health Organization - 2011

[2] Almomani, I. and A. AlSarheed (2016). "Enhancing outpatient clinics management software by reducing patients' waiting time." J Infect Public Health 9 (6): 734-743.

[3] Aeenparast, A., et al. (2015). "Waiting time for first outpatient visit in specialty level: assessing the provider related factors." Arch Iran Med 18 (3): 185-188.

[4] Doherty T, Chopra M, Tomlinson M, Oliphant N, Nsibande D, et al. Moving from vertical to intgrated child health programmes: experiences from a multi-country assessment of the Child Health Days approach in Africa. Trop Med Int Health. 2010; 15:296-305.
[5] Lawn JE, Rohde J, Rifkin S, Were M, Paul VK, et al. AlmaAta 30 years on: revolutionary, relevant, and time to revitalise. Lancet. 2008; 372:917-927.

[6] Topp SM, Chipukuma JM, Giganti M, Mwango LK, Chiko LM, et al. Strengthening health systems at facility-level: feasibility of integrating antiretroviral therapy into primary health care services in Lusaka, Zambia. PLoS One. 2010; 5:e11522.

[7] Wagner G, Ryan G, Taylor S. Formative evaluation of antiretroviral therapy scale-up efficiency in sub-Saharan Africa. Aids Patient Care and Stds. 2007; 21:871-887.

[8] olebunders R, Bukenya T, Pakker N, Smith O, Boeynaems V, et al. Assessment of the patient flow at the infectious diseases institute out-patient clinic, Kampala, Uganda. Aids CarePsychological and Socio-Medical Aspects of Aids/Hiv. 2007; 19:149-151.

[9] Hardon AP, Akurut D, Comoro C, Ekezie C, Irunde HF, et al. Hunger, waiting time and transport costs: time to confront challenges to ART adherence in Africa. AIDS Care. 2007; 19:658-665.

[10] Ward, P. R., et al. (2017). "'Waiting for' and 'waiting in' public and private hospitals: a qualitative study of patient trust in South Australia." BMC Health Serv Res 17 (1): 333. 